\title{
A predictive role for noncancerous prostate cells: low connexin-26 expression in radical prostatectomy tissues predicts metastasis
}

\author{
IV Bijnsdorp*,', L Rozendaal' ${ }^{2}$, RJA van Moorselaar' and AA Geldof' \\ 'Department of Urology, VU University Medical Center, De Boelelaan III 7 4FI 2, Amsterdam 108 I HV, The Netherlands; ${ }^{2}$ Department of Pathology, \\ VU University Medical Center, Amsterdam 1081 HV, The Netherlands
}

\begin{abstract}
BACKGROUND: It is important to identify markers that predict whether prostate cancer will metastasise. The adjacent noncancerous cells (influenced by the tumour cells) may also express potential markers. The objective of this study was to determine the influence of cancer cells on noncancerous cells and to assess the value of the cell-communication protein connexin-26 (Cx26) as a marker to predict the development of metastasis.

METHODS: The effect of conditioned medium (CM) from PrCa cells on in vitro noncancerous cell proliferation, migration and invasion and Cx26 expression was determined. Connexin-26 expression was investigated in prostatectomy tissues from 5I PrCa patients by immunohistochemistry and compared with various clinicopathological parameters.

RESULTS: Proliferation, migration and invasion of noncancerous cells were influenced by CM from the PrCa cell lines. Importantly, a clear relation was found between low Cx26 expression in the noncancerous tissue in prostatectomy sections and the risk of development of metastasis $(P<0.0002)$. Kaplan-Meier analysis showed a relation between low $\mathrm{C} \times 26$ expression in noncancerous tissues and time to biochemical recurrence $(P=0.0002)$.

CONCLUSION: Measuring CX26 expression in the adjacent noncancerous tissues (rather than cancer tissues) of prostatectomy sections could help to identify high-risk patients who may benefit from adjuvant therapy to decrease the risk of metastasis.

British Journal of Cancer (2012) 107, 1963-1968. doi: I0.1038/bjc.2012.500 www.bjcancer.com

Published online 20 November 2012

(c) 2012 Cancer Research UK
\end{abstract}

Keywords: prostate cancer; connexin-26; metastasis; prostatectomy; noncancerous tissues

Prostate cancer is the most common cancer diagnosed in males and the second leading cause of cancer-related death (Jemal et al, 2010). Many cases present with a slow growing, clinically unapparent form of prostate cancer. Others present with a fast growing, aggressive tumour that quickly metastasises. The cause of this variability is largely unknown. When prostate cancer has metastasised, no curative therapy is available. Hence, it is very important to find predictive factors that can identify the more aggressive forms of prostate cancer. Mostly, prostate cancer biomarkers are studied in prostate cancer tissues. However, the morphological normal (noncancerous) prostate cells may also be influenced by the tumour, as tumour and tumourinfiltrated cells (e.g., endothelial cells, fibroblasts and immune cells) secrete many factors that may change the behaviour of these noncancerous cells (Hanahan and Weinberg, 2000; Cunha et al, 2002; 2003). Thereby, the expression of genes and proteins may be changed in these noncancerous tissues of the prostate (Jia et al, 2011; Trevino et al, 2011). This aspect has not been studied thoroughly and may provide new perspectives in the biomarker research.

*Correspondence: Dr IV Bijnsdorp; E-mail: iv.bijnsdorp@vumc.nl Revised 2 October 2012; accepted 16 October 2012; published online 20 November 2012
For tumour growth, cell-to-cell communications are very important. Gap junction connexions (Cxs) are structures that are involved in cell-cell communications (Cronier et al, 2009, Naus and Laird, 2010). The gap junction is a specialised cell membrane channel that interconnects the cytoplasm of adjacent cells. Gap junction intercellular communication is involved in the growth and differentiation of cells and it has a role in maintaining homoeostasis of tissues (Krutovskikh et al, 2002). Gap junctions are described to be involved in cancer progression when downregulated in cancer cells (Krutovskikh et al, 1994; Kamibayashi et al, 1995; Tsai et al, 1996; Jinn et al, 1998; Czyż et al, 2012). Connexions are gap junction proteins that allow the transport of factors between cells, supporting synchronised post-translational modifications such as phosphorylation cascades (intracellular signalling). Gap junctions that are composed of Cxs have an essential role in intercellular communication, adhesion, cell proliferation and cell differentiation. Dysregulation of these Cxs has been related to tumour progression (Kamibayashi et al, 1995; Mehta et al, 1999; Habermann et al, 2002; Li et al, 2008). It is possible that the intercellular exchange of molecules involved in the growth and death of cells may occur through these gap junctions (Trosko and Chang, 2001).

Connexin-26 (Cx26) is a protein that is involved in gap junctions (Cronier et al, 2009). Connexin-26 has been previously described to have a role in the progression of various cancers, including 


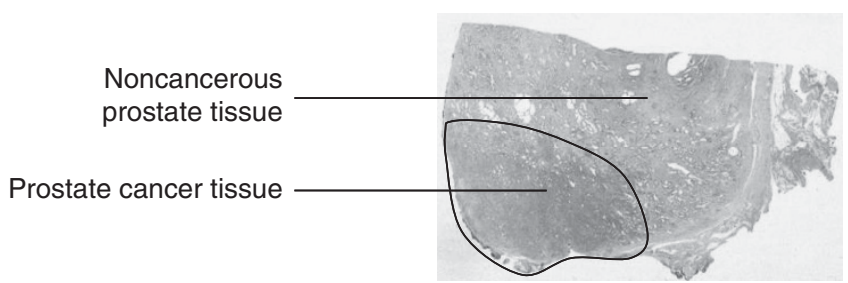

Figure I Haematoxylin- and eosin-stained tissue section derived from a radical prostatectomy specimen is shown, and both the tumour part and the noncancerous cells present in the rest of the specimen are indicated.

melanoma and colorectal cancer (Ezumi et al, 2008; Haass et al, 2010). However, a relation between Cx26 expression of the adjacent noncancerous tissues and progression has not been described. In this study, we determined the effect of prostate cancer cells on noncancerous prostate cell proliferation, migration and invasion, and the expression of $\mathrm{Cx} 26$. In addition, we assessed the expression levels of $\mathrm{Cx} 26$ in prostate tumour and in adjacent noncancerous tissues present in radical prostatectomy specimens (Figure 1). Connexin-26 expression in this material was characterised in relation to metastasis of the prostate cancer. We found a relation between the expression of $\mathrm{Cx} 26$ in the adjacent noncancerous tissues and the development of metastasis, which was detected months to years after radical prostatectomy.

\section{MATERIALS AND METHODS}

\section{Cell lines and preparation of conditioned medium}

The noncancerous prostate epithelial cells (PrECs) and prostate stromal cells (prSCs) were obtained from Lonza (Basel, Switzerland) and were cultured in EGM and SCGM bullet kit media (Lonza), respectively. LNCaP and PC3 cells (both derived from metastasis) were obtained from the American Type of Culture Collection (Rockville, MD, USA) and were cultured as monolayers in RPMI supplemented with $10 \%$ FCS. Cells were maintained in a humidified $5 \% \mathrm{CO}_{2}$ atmosphere at $37^{\circ} \mathrm{C}$. The conditioned medium (CM) from the cancer cells was prepared as described previously (Bijnsdorp et al, 2011). In brief, cancer cells were seeded $\left(2-2.5 \times 10^{6}\right.$ cells per T75 culture flask). After $24 \mathrm{~h}$, the medium was replaced by exactly $10 \mathrm{ml}$ serum-free RPMI. After 2 days, the medium was collected and filtered through a $0.22-\mu \mathrm{m}$ filter. Subsequently, the medium was concentrated $20 \times$ using Amicon Ultra 15 Centrifugal filters (Millipore, Billerica, MA, USA). For each experiment, the concentrated medium was diluted in cell line-specific medium. The CM is referred as CM-L (LNCaP) and CM-P (PC3). As controls, concentrated medium from RPMI was used (CM-R).

\section{Proliferation assay}

Prostate epithelial cell and prSC proliferation was determined by the sulforhodamine B (SRB) assay, as described previously (Bijnsdorp et al, 2010). In brief, 7000 cells per well were seeded in 96-well plates (Greiner Bio One, Frickenhausen, Germany). After $24 \mathrm{~h}$, cells were exposed to the CM of the cancer cells. Every day the medium was refreshed with CM. After $72 \mathrm{~h}$ of stimulation, cells were precipitated with trichloroacetic acid for $1 \mathrm{~h}$ at $4^{\circ} \mathrm{C}$, stained with SRB, solubilised with Tris and the optical density was measured at $540 \mathrm{~nm}$. Unstimulated controls were set to $100 \%$ cell proliferation.

\section{Transwell assay}

The transwell migration and invasion assay were carried out using transwell chambers with a fluorescence blocking $8-\mu \mathrm{m}$ pore filter insert (no. 35-1152; HTS Fluoroblock Insert, Falcon, Becton
Dickinson Labware, Bedford, MA, USA; Bijnsdorp et al, 2011). For the invasion assay, the insert was coated overnight at room temperature (RT) with $100 \mu \mathrm{l}$ matrigel $\left(50 \mathrm{ng} \mathrm{ml}^{-1}\right.$ in PBS; Sigma Aldrich Chemicals, Zwijndrecht, The Netherlands). For the migration assay, the insert was left uncoated. Cells (150000 per insert) were seeded in serum-free medium. In the lower compartment, the CM was diluted in appropriate cell growth medium. Cells were allowed to migrate/invade for $8 \mathrm{~h}$. About $5 \mu \mathrm{m}$ calcein-AM was added $30 \mathrm{~min}$ before analysis to the lower compartment and fluorescently labelled cells were counted using a fluorescence microscope.

\section{Fluorescent staining}

Fluorescent staining was performed as described previously (Bijnsdorp et al, 2010). In brief, cells were grown to $90-100 \%$ confluency, a confluency at which the cells were able to form detectable intercellular channels, and were subsequently exposed to the $\mathrm{CM}$ for $6 \mathrm{~h}$, after which cells were fixed, permeabilised with $0.2 \%$ Triton X-100 in PBS, blocked with 3\% BSA (RT) and stained for Cx26 (1:200; Invitrogen, Camarillo, CA, USA) overnight at $4{ }^{\circ} \mathrm{C}$. The secondary antibody ( $\alpha$-mouse-FITC; $1: 200$; Dako, Glostrup, Denmark) was added together with Hoechst 33342 (Sigma Aldrich Chemicals) $(1: 2000)$ for $1 \mathrm{~h}$ at RT. Fluorescence microscopy analysis was carried out using an inverted Leica (Leica Cambridge Ltd, Cambridge, UK) DMIRB/E fluorescence microscope.

\section{Western blotting}

Western blotting was performed as described previously (Bijnsdorp et al, 2010). In brief, cells were exposed to the CM for $6 \mathrm{~h}$ and subsequently lysed in lysis buffer (Cell Signalling Technology Inc., Danvers, MA, USA). From each condition, $30 \mu \mathrm{g}$ of protein was separated on a $10 \%$ SDS-PAGE and electroblotted onto polyvinylidenedifluoride (PVDF) membranes (Millipore, Billerica, MA, USA Immobilon-FL PVDF). Subsequently, the membranes were blocked for $1 \mathrm{~h}$ at $\mathrm{RT}$ in blocking buffer and incubated overnight at $4{ }^{\circ} \mathrm{C}$ with the primary antibody (Anti-Cx26, (clone CX-1E8, 1:1000; Invitrogen) and subsequently incubated with the secondary antibody (1:10000 goat- $\alpha$-mouse-IRDye or goat- $\alpha$-rabbit-IRDye (Westburg, Leusden, The Netherlands)) for $1 \mathrm{~h}$ at RT. The bands were scanned using the Odyssey Infrared Imager (Westburg).

\section{Patients and tissues}

Fifty-one patients with clinically localised adenocarcinoma of the prostate were selected for this study. Selection criteria were followup time and tumour present in the tissue blocks. Radical prostatectomies were performed between 1994 and 2011 at the Department of Urology, VU University Medical Center in Amsterdam, The Netherlands. Of these patients, the preoperative PSA values, clinical and pathological classification and Gleason scores were available. Postoperatively, the patients were scheduled for regular follow-up visit at the institutional outpatient clinic (5-178 months). Biochemical progression was defined as rising postoperative PSA levels by $>0.2 \mathrm{ng} \mathrm{ml}^{-1}$, confirmed in a consecutive visit. Clinical progression was defined as detection of metastasis, which was detected 1-44 months after surgery.

\section{Immunohistochemistry}

Immunohistochemistry was performed on 3- $\mu \mathrm{m}$ thick paraffinembedded sections of radical prostatectomy specimens. Slides were deparaffinised by steps of xylene and subsequently rehydrated by decreasing concentrations of ethanol. Endogenous peroxide expression was blocked by incubation with $0.3 \% \mathrm{H}_{2} \mathrm{O}_{2}$ in methanol for $30 \mathrm{~min}$. Slides were heated for antigen retrieval in 
$1 \mathrm{~mm}$ Tris/EDTA buffer ( $\mathrm{pH}$ 9.0). Slides were blocked with $2 \%$ normal goat serum (Dako) for $10 \mathrm{~min}$ at RT and exposed for $1 \mathrm{~h}(\mathrm{RT})$ to the primary antibody against anti-Cx26 (1:100; Invitrogen). After incubation, sections were washed and incubated with post-antibody blocking solution (Immunologic, Duiven, The Netherlands) for $15 \mathrm{~min}$ (RT). Subsequently, slides were washed and incubated with Brightvision-plus (Immunologic) for $60 \mathrm{~min}$ at RT. Peroxide was revealed by AEC solution (Invitrogen). Slides were counterstained with haematoxylin and were covered in Kaisers glycerol (Merck KGAa, Darmstadt, Germany).

\section{Evaluation of IHC}

Blinded for the clinical parameters, including age, PSA values, Gleason, progression and metastasis development, immunohistochemically stained slides were reviewed independently by an experienced pathologist and an experienced researcher. Connexin26 staining of the whole-tissue section was scored for percentage of glands positive and staining intensity $(0-3)$ for both cancer and noncancerous tissues (Figure 1). These values were multiplied, providing scores from 0 to 300 . Statistical analysis was performed by $\chi^{2}$-test for the significance between the patient groups.

\section{RESULTS}

\section{In vitro behaviour of noncancerous prostate cells}

To evaluate the effect of prostate cancer cells on noncancerous prostate cells, CM from LNCaP and PC3 cells was collected and concentrated. This medium was subsequently used to stimulate the noncancerous prEC and prSCs. The effect of the CM-L and CM-P on proliferation, migration and invasion of prECs and prSCs was determined by the SRB assay (proliferation) and the transwell assay (migration/invasion). Interestingly, prECs and prSCs responded differently to the CM. Prostate stromal cell proliferation was increased by CM-P, whereas prEC cell proliferation decreased by both CM-L and CM-P (Figure $2 \mathrm{~A}$ ). The migration and invasion of prEC cells were highly increased, while not significantly affected in prSCs (Figures $2 \mathrm{~B}$ and $\mathrm{C}$ ).

As cell communication is important in the behaviour of cells, we determined the expression level of the communication protein, $\mathrm{Cx} 26$ by western blotting. The expression of $\mathrm{Cx} 26$ was decreased in both prECs and prSCs after incubation with CM-L and CM-P (Figure 3A). In addition, we evaluated Cx26 expression by immunofluorescent staining. The PrECs and prSCs were grown to about $90 \%$ confluency and subsequently exposed to CM-L or CM-P. We observed channels to a high extent in untreated controls, while still detectable but to a very low extent after exposure to both the CM-L and CM-P. Taken together, the decreased Cx26 expression and decreased formation of intercellular channels indicate a disturbed intercellular communication (Figure 3B).

\section{Connexin-26 expression in patient tissues and clinical outcome}

To study whether the expression of $\mathrm{Cx} 26$ was decreased in the adjacent noncancerous region of prostate cancer, we evaluated its expression in prostate cancer tissues of 51 patients. In Table 1, the patients characteristics are summarised. The mean and median age at time of radical prostatectomy were 64 years. Gleason scores ranged from 5 to 10 . During the follow-up, 35\% developed metastasis and $47 \%$ showed biochemical recurrence.

A

A
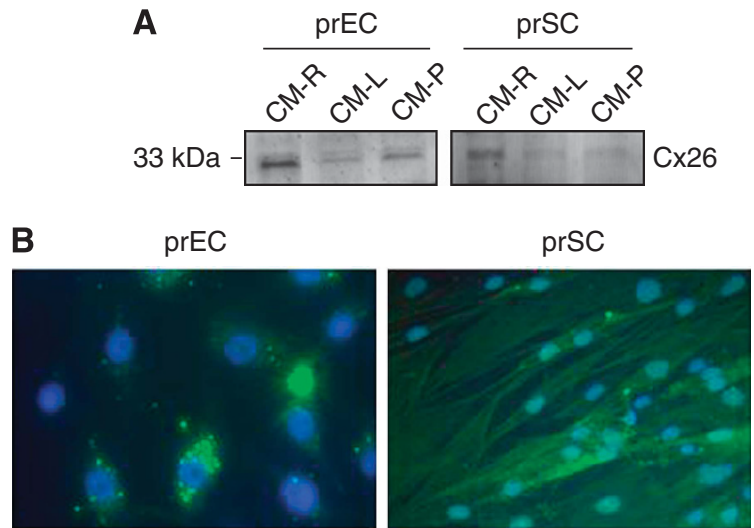

CM-R
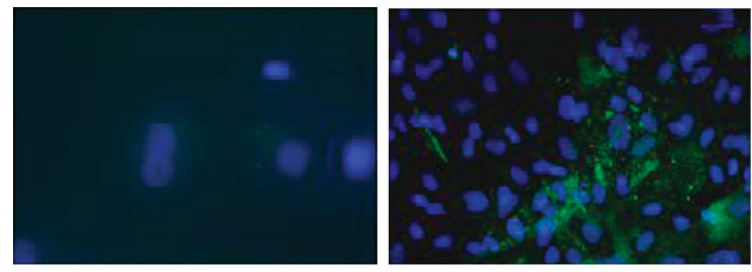

CM-L
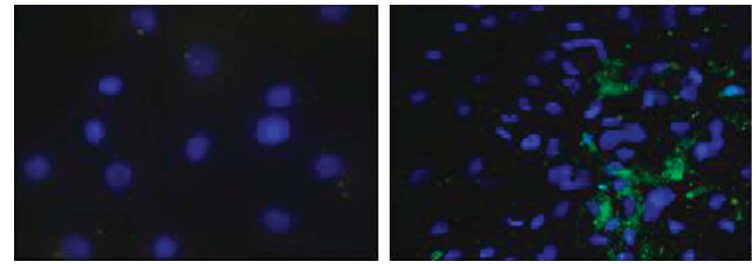

CM-P

Figure 3 (A) Western blot of $\mathrm{C} \times 26$ expression in prECs and prSCs after 6-h stimulation with either CM-L or CM-P. (B) Immunofluorescent staining of $\mathrm{C} \times 26$ in prECs and prSCs after 6-h stimulation with CM-L or CM-P.
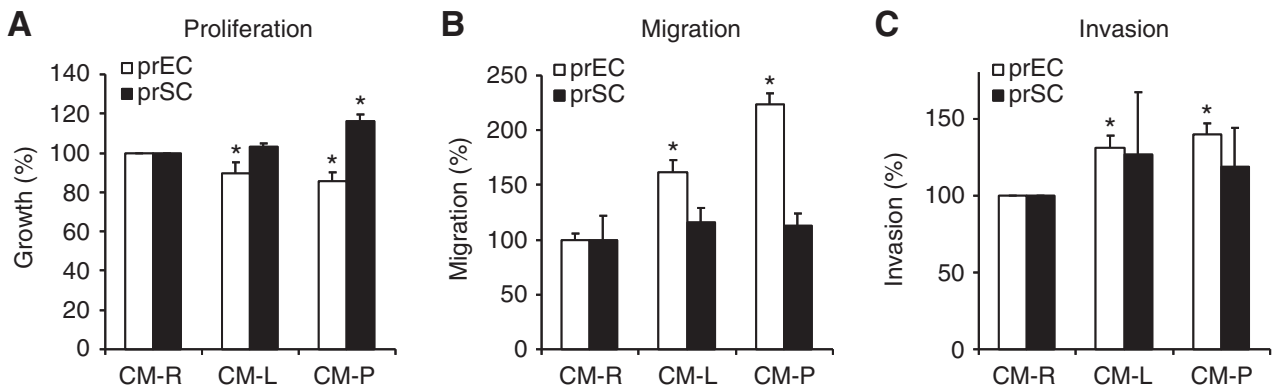

Figure 2 Cell behaviour of prECs and prSCs after stimulation with the conditioned media of LNCaP cells (CM-L) or PC3 cells (CM-P). (A) proliferation after 72-h stimulation with the CM. (B) Migration after 8-h stimulation with the CM. (C) Invasion after 8-h stimulation with the CM. The values of the three graphs represent means of at least three to five independent experiments \pm s.e.m., relative to $C M-R$ responses. *Significant differences between the $C M$ stimulated cells and untreated controls $(C M-R)$ are indicated in the graph $(P<0.05)$. 
Table I Characteristics of study participants $(n=5 \mathrm{I})$

\begin{tabular}{|c|c|}
\hline Age (median) & $51-83(64)$ \\
\hline \multicolumn{2}{|l|}{ Gleason score, n (\%) } \\
\hline $5-6$ & $20(39)$ \\
\hline 7 & $18(36)$ \\
\hline $8-10$ & $13(26)$ \\
\hline \multicolumn{2}{|l|}{ Clinical stage, n (\%) } \\
\hline CTI & $17(33)$ \\
\hline cT2 & $28(57)$ \\
\hline cT3 & $5(10)$ \\
\hline \multicolumn{2}{|l|}{ Metastasis, n (\%) } \\
\hline Yes & $18(35)$ \\
\hline No & $33(65)$ \\
\hline \multicolumn{2}{|c|}{ Biochemical recurrence, n (\%) } \\
\hline Yes & $24(47)$ \\
\hline No & $27(53)$ \\
\hline \multicolumn{2}{|c|}{ Cx26 expression tumour tissue, $\mathrm{n}(\%)$} \\
\hline Score $<100$ (low) & $40(87)$ \\
\hline Score $>100$ (high) & $11(22)$ \\
\hline \multicolumn{2}{|c|}{ Cx26 expression noncancerous tissue, $\mathrm{n}$ (\%) } \\
\hline Score < 100 (low) & $26(51)$ \\
\hline Score $>100$ (high) & $25(49)$ \\
\hline
\end{tabular}

Abbreviation: Cx26 = connexin-26.

Connexin-26 expression was observed immunohistochemically in $94 \%$ of the patients. Connexin-26 was almost exclusively expressed in the cytoplasm of the luminal epithelial cells (Figure 4). The benign prostatic hyperplastic regions showed a comparable staining distribution compared with 'healthy' tissues, but the atrophic regions were negative for $\mathrm{Cx} 26$ expression. A significant association $(P<0.0002)$ was found between a low $\mathrm{Cx} 26$ score in noncancerous tissues and the subsequent formation of distant metastasis (Figure 5A). These metastases were detected between 1 month to 4 years after radical prostatectomy. No relation was found between $\mathrm{Cx} 26$ expression in the tumour tissue and occurrence of metastasis (Figure 5B). The expression levels of Cx26 in the tumour tissues were low, with a median score of 30 , which is considerably lower than the average score in the noncancerous prostate tissue ( $120 ; P=0.0007$; data not shown).

The Kaplan-Meier estimates by high or low Cx26 expression in noncancerous tissues are shown in Figure 5C. For discrimination between a high or low expression, we chose a cutoff value of 100 , which was based on the differences in expression between patients who developed metastasis and patients without metastasis (Figure 5A). A value of $>100$ was therefore considered as a high Cx26 expression. With this cutoff, the time to biochemical recurrence was significantly shorter for patients with a low Cx26 expression $(P=0.0002)$, which is in relation to the increased number of metastatic patients in this group (with a hazard ratio of 3.449 in a multivariate analysis). Univariate Cox proportional hazards analysis showed that $\mathrm{Cx} 26$ expression in the nontumourcontaining tissue, Gleason score and PSA levels significantly correlated independently with the time to progression (Table 2). Multivariate Cox proportional hazards analysis revealed that time to progression was associated with tumour stage, Gleason score and Cx26 expression in the noncancerous prostate tissues (Table 2), but not with the PSA levels.

\section{DISCUSSION}

This study shows that a decreased Cx26 expression in noncancerous prostate tissue was related to an increased risk to develop
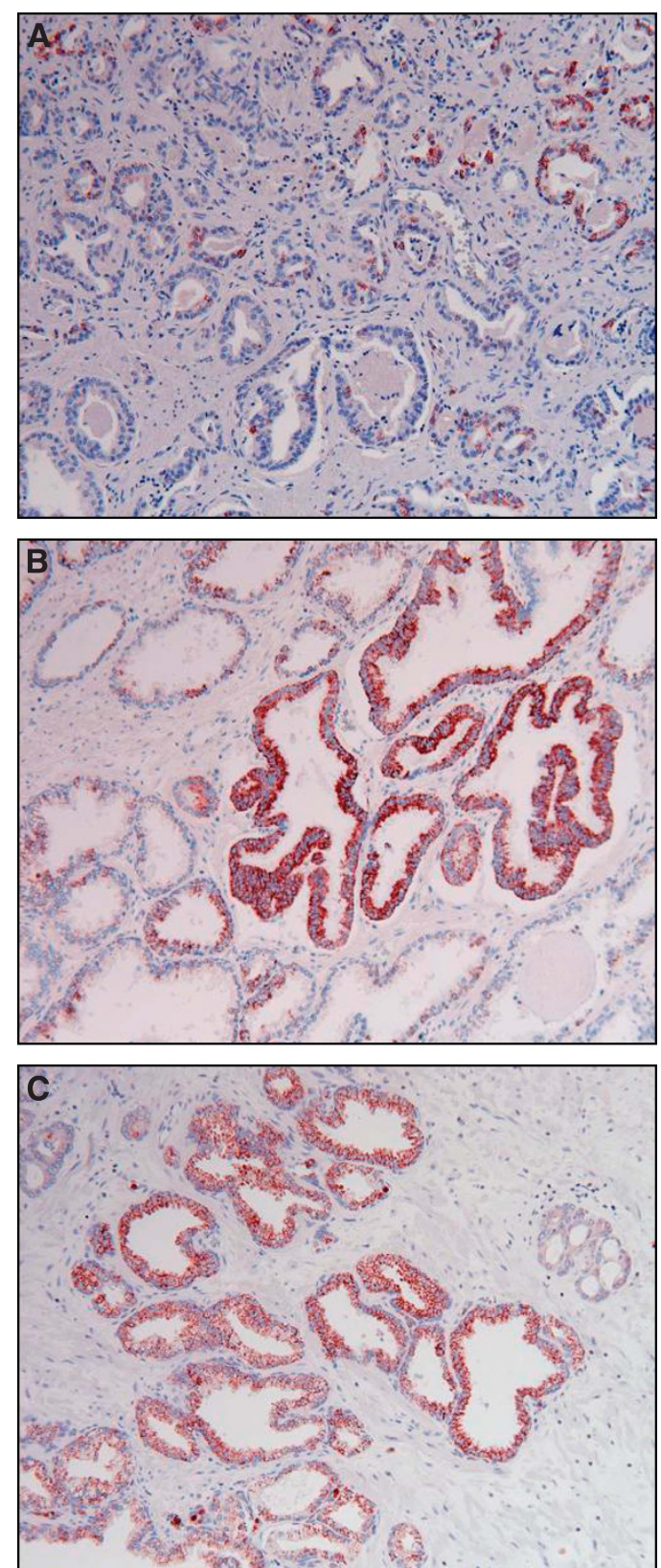

Figure 4 Expression pattern of $\mathrm{C} \times 26$ in prostate tissues. (A) Representative example of Cx26 expression in tumour tissue. (B) Connexin-26 expression in the noncancerous prostate tissue (within the same slide as $\mathbf{A}$ ) of the radical prostatecomy specimen. (C) Connexin-26 expression in the noncancerous prostate tissue of another patient.

metastasis. It is especially notable that the expression of $\mathrm{Cx} 26$ was decreased, months to years before the diagnosis of the metastasis. The approach to study biomarkers in the noncancerous parts of the prostate will provide novel opportunities in the investigation of prostate cancer biology and metastasis. The expression of $\mathrm{Cx} 26$ may be used to identify metastatic prostate cancer patients after radical prostatectomy in a relatively early stage. When $\mathrm{Cx} 26$ is expressed at low levels, these patients may benefit from adjuvant (postoperative) therapy to decrease the risk of development of distant metastasis.

Mostly, biomarkers are studied in the tumour or tumourassociated stromal cells. At this moment the knowledge about the complexity of the role of the tumour microenvironment in 
A

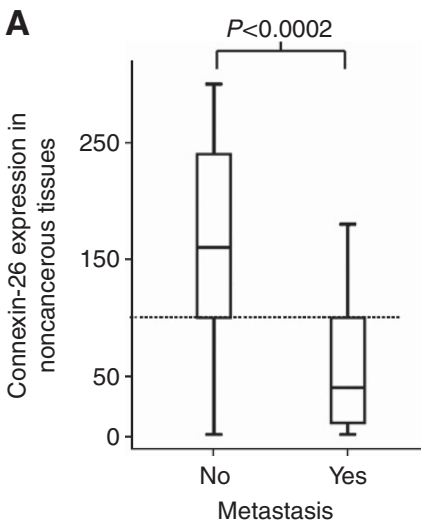

B

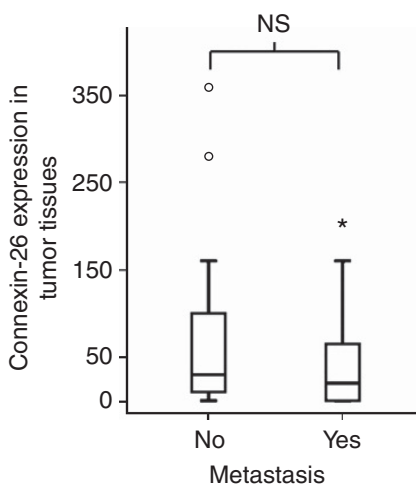

C

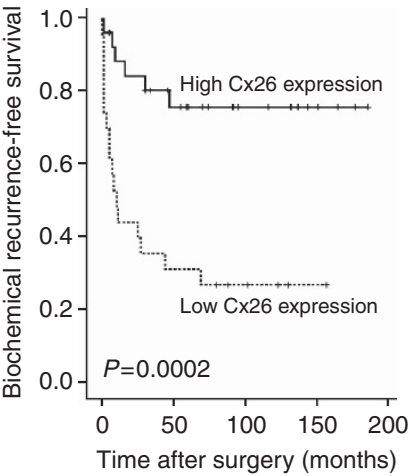

Figure 5 Connexin-26 expression in relation to postoperative development of metastasis. (A) Box plot showing the relation between Cx26 expression in the noncancerous tissues and the development of metastasis. The line within the box plot corresponds to the median value, the box length to the interquartile range, and the lines emanating from the box (whiskers) extend to the smallest and largest observations. The dotted line indicates the cutoff value of 100, which represents a high/low expression of Cx26. (B) Box plot showing the relation between Cx26 expression in the tumour tissues and the development of metastasis. (C) Kaplan-Meier biochemical recurrence-free survival curves according to the expression of Cx26 in the noncancerous prostate tissue. High expression was defined when Cx26 score was $\geqslant 100$, and a low expression was defined when the Cx26 score was $>100$. The cutoff value of 100 was chosen based on the differences between Cx26 expression in the noncancerous tissues of patients with and without metastasis. Statistical difference was analysed by the log-rank test $(P=0.0002)$. Outliers are indicated by * and ${ }^{\circ}$.

Table 2 Uni- and multivariate analyses of prognostic factors for time to biochemical recurrence

\begin{tabular}{|c|c|c|c|c|}
\hline \multirow[b]{2}{*}{ Variables } & \multicolumn{2}{|l|}{ Univariate } & \multicolumn{2}{|l|}{ Multivariate } \\
\hline & HR ( $95 \%$ Cl) & $P$-value & HR ( $95 \%$ Cl) & $P$-value \\
\hline $\begin{array}{l}\text { Tumour stage } \\
\text { Gleason } \\
\text { PSA }\end{array}$ & $\begin{array}{l}2.829(1.370-5.841) \\
1.818(1.377-2.401) \\
1.019(1.001-1.039)\end{array}$ & $\begin{array}{l}0.005 \\
0.00003 \\
0.05\end{array}$ & $\begin{array}{l}4.853(1.740-13.533) \\
5.368(1.742-16.546) \\
1.016(0.991-1.041\end{array}$ & $\begin{array}{l}0.003 \\
0.003 \\
0.2\end{array}$ \\
\hline $\begin{array}{l}\text { Biomarker } \\
\text { Cx26 expression } \\
\text { in nontumorous } \\
\text { prostate tissue }\end{array}$ & $4.785(1.875-12.214)$ & 0.001 & $3.449(1.221-9.748)$ & 0.02 \\
\hline
\end{tabular}

Abbreviations: $\mathrm{Cls}=$ confidence intervals; $\mathrm{C} \times 26=$ connexin-26; $\mathrm{HR}=$ hazard ratio; PSA = prostate-specific antigen

(prostate) cancer progression is increasing rapidly (Cunha et al, 2002; 2003; Alberti, 2006; Hanahan and Weinberg, 2011). Cancer cells and tumour-infiltrated cells are known to secrete many factors, such as growth factors and hormones, that have a role in cell signalling. These factors may potentially diffuse to the noncancerous parts of the prostate and subsequently affect these normal cells in their behaviour. Connexins are regulated by growth factors and hormones, which has been described in various cell systems (Maldonado et al, 1988; Madhukar et al, 1989; Stagg and Fletcher, 1990; Yu et al, 1994; Carruba et al, 2002). The disturbed Cxs expression in prostate cancer may be related to the hormones and growth factors that are secreted by the cancer and its microenvironment. The relation behind the decreased $\mathrm{Cx} 26$ expression in the noncancerous regions and the increased risk of metastasis might be caused by a decreased adhesion regulation, mediated by an interaction with the focal adhesion kinase (Tate et al, 2006). The disturbed intercellular communication between the tumour and noncancerous tissue may finally result in more aggressive cancer cells with a higher metastatic potential. The molecular mechanisms underlying this hypothesis need to be investigated in future studies.

The number of positive surgical margins in the patient group who eventually developed metastasis was higher (79\%) than in the nonmetastatic group (32\%). For patients with positive surgical margins, Cx26 staining may therefore be a predictive stratification marker for prostate cancer metastasis. In addition, the morphological healthy prostate cells in prostatectomy tissues are often used as healthy controls (Tsai et al, 1996; Habermann et al, 2002). Our data suggest that these morphologically healthy prostate cells may not be proper controls. In addition, some studies already indicated that the adjacent benign (normal) prostate cells can have a predictive role for the presence of cancer (Isharwal et al, 2010; Jia et al, 2011). Therefore, caution is recommended for using these noncancerous cells as healthy controls.

Connexin-26 was previously described to be highly expressed in the luminal cells of the normal prostate epithelium (El-Alfy et al, 2000). This is in agreement with the observations in this study. The loss of gap junctions is considered to be a critical step to prostate cancer progression (Mehta et al, 1999). Connexin-26 expression has been studied in several other tumour types, such as colorectal, gastric and oesophageal squamous cell carcinoma (Inose et al, 2009; Liu et al, 2010; Nomura et al, 2010). A loss of Cx expression in the cancer cells has been described for various of these tumour types (Mehta et al, 1999; Nomura et al, 2010; Benko et al, 2011). This is in agreement with our findings in this study. Although the roles of Cxs in cancer progression seem to vary, in general Cxs appear to have a tumour-suppressive function.

We show a novel correlation between a low Cx26 expression in noncancerous prostate tissue and the development of metastasis within 4 years after radical prostatectomy. This expression can therefore be considered as a marker, which can potentially be used to identify high-risk patients with localised disease. When patients have a low $\mathrm{Cx} 26$ expression in noncancerous prostate tissue, adjuvant postoperative therapy can be given to decrease the chance of developing tumour metastasis. Additional studies examining the association between Cx26 expression and the development of metastasis are recommended.

\section{ACKNOWLEDGEMENTS}

The W Pon foundation is kindly acknowledged for financially supporting this research.

\section{Conflict of interest}

The authors declare no conflict of interest. 


\section{REFERENCES}

Alberti C (2006) Prostate cancer progression and surrounding microenvironment. Int J Biol Markers 21: 88-95

Benko G, Spajić B, Demirović A, Stimac G, Kru Sbreve Lin B, Tomas D (2011) Prognostic value of connexin43 expression in patients with clinically localized prostate cancer. Prostate Cancer Prostatic Dis 14: 90-95

Bijnsdorp IV, Capriotti F, Kruyt FA, Losekoot N, Fukushima M, Griffioen AW, Thijssen VL, Peters GJ (2011) Thymidine phosphorylase in cancer cells stimulates human endothelial cell migration and invasion by the secretion of angiogenic factors. Br J Cancer 104: 1185-1192

Bijnsdorp IV, Peters GJ, Temmink OH, Fukushima M, Kruyt FA (2010) Differential activation of cell death and autophagy results in an increased cytotoxic potential for trifluorothymidine compared to 5-fluorouracil in colon cancer cells. Int J Cancer 126: 2457-2468

Carruba G, Webber MM, Quader ST, Amoroso M, Cocciadiferro L, Saladino F, Trosko JE, Castagnetta LA (2002) Regulation of cell-to-cell communication in non-tumorigenic and malignant human prostate epithelial cells. Prostate 50: 73-82

Cronier L, Crespin S, Strale PO, Defamie N, Mesnil M (2009) Gap junctions and cancer: new functions for an old story. Antioxid Redox Signal 11: 323-338

Cunha GR, Hayward SW, Wang YZ (2002) Role of stroma in carcinogenesis of the prostate. Differentiation 70: 473-485

Cunha GR, Hayward SW, Wang YZ, Ricke WA (2003) Role of the stromal microenvironment in carcinogenesis of the prostate. Int J Cancer 107: $1-10$

Czyż J, Szpak K, Madeja Z (2012) The role of connexins in prostate cancer promotion and progression. Nat Rev Urol 9: 274-282

El-Alfy M, Pelletier G, Hermo LS, Labrie F (2000) Unique features of the basal cells of human prostate epithelium. Microsc Res Tech 51: 436-446

Ezumi K, Yamamoto H, Murata K, Higashiyama M, Damdinsuren B, Nakamura Y, Kyo N, Okami J, Ngan CY, Takemasa I, Ikeda M, Sekimoto M, Matsuura N, Nojima H, Monden M (2008) Aberrant expression of connexin 26 is associated with lung metastasis of colorectal cancer. Clin Cancer Res 14: 677-684

Haass NK, Ripperger D, Wladykowski E, Dawson P, Gimotty PA, Blome C, Fischer F, Schmage P, Moll I, Brandner JM (2010) Melanoma progression exhibits a significant impact on connexin expression patterns in the epidermal tumor microenvironment. Histochem Cell Biol 133: 113-124

Habermann H, Ray V, Habermann W, Prins GS (2002) Alterations in gap junction protein expression in human benign prostatic hyperplasia and prostate cancer. J Urol 167: 655-660

Hanahan D, Weinberg RA (2000) The hallmarks of cancer. Cell 100: 57-70

Hanahan D, Weinberg RA (2011) Hallmarks of cancer: the next generation. Cell 144: 646-674

Inose T, Kato H, Kimura H, Faried A, Tanaka N, Sakai M, Sano A, Sohda M, Nakajima M, Fukai Y, Miyazaki T, Masuda N, Fukuchi M, Kuwano H (2009) Correlation between connexin 26 expression and poor prognosis of esophageal squamous cell carcinoma. Ann Surg Oncol 16: 1704-1710

Isharwal S, Makarov DV, Carter HB, Epstein JI, Partin AW, Landis P, Marlow C, Veltri RW (2010) DNA content in the diagnostic biopsy for benign-adjacent and cancer-tissue areas predicts the need for treatment in men with T1c prostate cancer undergoing surveillance in an expectant management programme. BJU Int 105: 329-333

Jemal A, Siegel R, Xu J, Ward E (2010) Cancer statistics. CA Cancer J Clin 60: 77-300

Jia Z, Wang Y, Sawyers A, Yao H, Rahmatpanah F, Xia XQ, Xu Q, Pio R, Turan T, Koziol JA, Goodison S, Carpenter P, Wang-Rodriguez J,
Simoneau A, Meyskens F, Sutton M, Lernhardt W, Beach T, Monforte J, McClelland M, Mercola D (2011) Diagnosis of prostate cancer using differentially expressed genes in stroma. Cancer Res 71: 2476-2487

Jinn Y, Ichioka M, Marumo F (1998) Expression of connexin32 and connexin43 gap junction proteins and E-cadherin in human lung cancer. Cancer Lett 127: 161-169

Kamibayashi Y, Oyamada Y, Mori M, Oyamada M (1995) Aberrant expression of gap junction proteins (connexins) is associated with tumor progression during multistage mouse skin carcinogenesis in vivo. Carcinogenesis 16: 1287-1297

Krutovskikh VA, Piccoli C, Yamasaki H (2002) Gap junction intercellular communication propagates cell death in cancerous cells. Oncogene 21: 1989-1999

Krutovskikh V, Mazzoleni G, Mironov N, Omori Y, Aguelon AM, Mesnil M, Berger F, Partensky C, Yamasaki H (1994) Altered homologous and heterologous gap-junctional intercellular communication in primary human liver tumors associated with aberrant protein localization but not gene mutation of connexin 32. Int J Cancer 56: 87-94

Li Z, Zhou Z, Welch DR, Donahue HJ (2008) Expressing connexin 43 in breast cancer cells reduces their metastasis to lungs. Clin Exp Metastasis 25: 893-901

Liu X, Furuya T, Li D, Xu J, Cao X, Li Q, Xu J, Xu Z, Sasaki K, Liu X (2010) Connexin 26 expression correlates with less aggressive phenotype of intestinal type-gastric carcinomas. Int J Mol Med 25: 709-716

Maldonado PE, Rose B, Loewenstein WR (1988) Growth factors modulate junctional cell-to-cell communication. J Membr Biol 106: 203-210

Madhukar BV, Oh SY, Chang CC, Wade M, Trosko JE (1989) Altered regulation of intercellular communication by epidermal growth factor, transforming growth factor-beta and peptide hormones in normal human keratinocytes. Carcinogenesis 10: 13-20

Mehta PP, Perez-Stable C, Nadji M, Mian M, Asotra K, Roos BA (1999) Suppression of human prostate cancer cell growth by forced expression of connexin genes. Dev Genet 24: 91-110

Naus CC, Laird DW (2010) Implications and challenges of connexin connections to cancer. Nat Rev Cancer 10: 435-441

Nomura S, Maeda K, Noda E, Inoue T, Fukunaga S, Nagahara H, Hirakawa $\mathrm{K}$ (2010) Clinical significance of the expression of connexin26 in colorectal cancer. J Exp Clin Cancer Res 29: 79

Stagg RB, Fletcher WH (1990) The hormone-induced regulation of contactdependent cell-cell communication by phosphorylation. Endocr Rev 11: 302-325

Tate AW, Lung T, Radhakrishnan A, Lim SD, Lin X, Edlund M (2006) Changes in gap junctional connexin isoforms during prostate cancer progression. Prostate 66: 19-31

Trevino V, Tadesse MG, Vannucci M, Al-Shahrour F, Antczak P, Durant S, Bikfalvi A, Dopazo J, Campbell MJ, Falciani F (2011) Analysis of normaltumour tissue interaction in tumours: prediction of prostate cancer features from the molecular profile of adjacent normal cells. PLoS One 6: e16492

Trosko JE, Chang CC (2001) Mechanism of up-regulated gap junctional intercellular communication during chemoprevention and chemotherapy of cancer. Mutat Res 480-481: 219-229

Tsai H, Werber J, Davia MO, Edelman M, Tanaka KE, Melman A, Christ GJ, Geliebter J (1996) Reduced connexin 43 expression in high grade, human prostatic adenocarcinoma cells. Biochem Biophys Res Commun 227: 64-69

Yu W, Dahl G, Werner R (1994) The connexin43 gene is responsive to oestrogen. Proc Biol Sci 255: 125-132

This work is published under the standard license to publish agreement. After 12 months the work will become freely available and the license terms will switch to a Creative Commons Attribution-NonCommercial-Share Alike 3.0 Unported License. 